\title{
A experiência com a doença: da entrevista à narrativa
}

I 1 Everardo Duarte Nunes, ${ }^{2}$ Marcelo Eduardo Pfeiffer Castellanos,

${ }^{3}$ Nelson Filice de Barros I

Resumo: O artigo ressalta a importância da narrativa como forma de descrever as experiências vividas, no caso especial da experiência com a doença. Toma como ponto de partida a narrativa como instrumento de pesquisa.

O material coletado na entrevista teve dupla finalidade: servir para treinamento de pós-graduandos nas técnicas da entrevista e para situar a problemática de saúde de um grupo de trabalhadores com diagnósticos de doenças crônicas como hipertensão, diabetes, lombalgias, etc. Buscaram-se relatos feitos em uma única entrevista, situando o adoecimento no contexto da história de vida, visando a captar a "vivência" do sujeito e seu enfrentamento do problema da doença como usuários de um centro de saúde de uma cidade do Estado de São Paulo. Em relação à organização do material, optouse pela reorganização da história oral elaborando uma narrativa com as informações obtidas. Portanto, esta é uma narrativa da narrativa original que, a partir de uma entrevista semiestruturada, foi formatada como um estudo de caso com enfoque biográfico, com o objetivo de entrever elementos da história de vida, da trajetória vivenciada pelo sujeito em seu processo de adoecimento, assim como de seu itinerário terapêutico. Conclui-se que o trabalho narrativo representa um importante recurso na produção do conhecimento, seja na perspectiva do ensino, seja na da pesquisa e do cuidado.

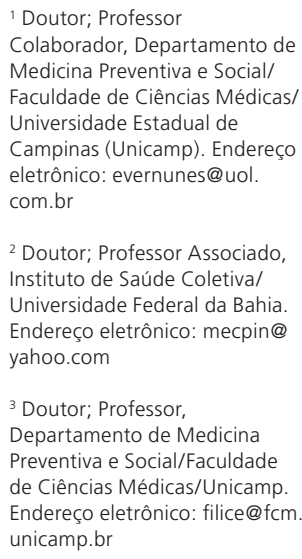

${ }^{2}$ Doutor; Professor Associado, Instituto de Saúde Coletiva/ Universidade Federal da Bahia. Endereço eletrônico: mecpin@ yahoo.com

${ }^{3}$ Doutor; Professor,

Departamento de Medicina Preventiva e Social/Faculdade de Ciências Médicas/Unicamp. Endereço eletrônico: filice @fcm. unicamp.br 

descrever o tempo vivido, salvo sob a forma de uma narrativa. [...] A narrativa imita a vida, a vida imita a narrativa. (BRUNER, 1987, p. 12-13).

\section{Introdução}

Afirmar que a narrativa permeia a vida humana é um lugar comum, mas necessário, e a sua contínua redescoberta no campo da pesquisa comprova sua importância e possibilidades para a compreensão da condição humana. Amplamente conhecida no campo literário e linguístico, torna-se presença obrigatória nas ciências sociais a partir dos anos de 1980. Sendo uma forma de pensar, enredando cognição, imaginação e ficção, materializa-se como um construto que assume visibilidade em periódicos, artigos, livros e dicionários, transitando pelos meandros das práticas pedagógicas e científicas. Nas décadas seguintes, torna-se tema presente em inúneros trabalhos, como os de Kleinman (1988), Mattingly e Garro (1994), Cunha (1997), Charon (2004, 2006), Czarniawska (2006), Fonte, (2006), Greenhalgh e Hurwitz (1999), Hydén (1997), Robinson (1990), Silva e Trentini (2002) e, além disso, converte-se em movimento presente em congressos, grupos de estudos e associações. ${ }^{1}$

Realização estética e científica, a narrativa "sugere a emergência de um outro caminho para o movimento dos 'novos paradigmas' e de um aprimoramento do método científico pós-positivista” (Brockmeier; Harré, 2003, p. 525). Portanto, as reflexões feitas sobre a narrativa dirigidas a aspectos metodológicos e epistemológicos da produção do conhecimento não se restringem ao seu uso instrumental na produção do material empírico ("coleta de dados"). Essas reflexões incidem sobre as próprias bases e lógicas que estruturam a produção de um tipo de conhecimento que tem na reelaboração dos relatos e observações, efetuados por pesquisados e pesquisadores, a construção de interpretaçôes validadas cientificamente.

Não trataremos da crescente literatura que, na área da saúde, utiliza a narrativa, mas daqueles trabalhos que importam diretamente à temática aqui abordada. Lira, Catrib e Nations (2003) assinalam a importância da narrativa para a "reconstrução da experiência do adoecer", recuperando alguns trabalhos que seguem essa linha de argumentação. Esses autores citam um trabalho 
extremamente importante que faz uma revisão de 2011 estudos científicos sobre a "pesquisa narrativa", na qual aparece uma tipologia bastante interessante do ponto de vista metodológico. Os autores situam três domínios principais da narrativa nos estudos qualitativos:

a) estudos em que a narrativa é usada para a investigação de qualquer questão de pesquisa, essa pode ser usada em um estudo piloto ou em combinação com outros métodos; b) estudos em que ela investiga a narrativa como seu precipuo de pesquisa; c) estudos sobre a filosofia e a metodologia das abordagens qualitativas de pesquisa, entre elas a narrativa" (LIEBRICH et al. apud LIRA; CATRIB; NATIONS, 2003, p. 96).

Gerhardt (1990) aborda a consolidação da pesquisa qualitativa como uma perspectiva metodológica legitimada no campo científico, em trabalhos que tomaram o adoecimento crônico como objeto de investigação, salientando que

nem a diretriz principal da sociologia da saúde nem a medicina conseguiam realizar uma incorporação adequada das experiências autênticas do adoecimento crônico em seus respectivos conhecimentos básicos. [...] Nas duas décadas seguintes aos anos 60, no entanto, o foco de discussão alterou-se. As doenças crônicas são agora vistas também sob a perspectiva da normalização [e não do desvio], enquanto as pesquisas qualitativas tornaram-se propensas para [...] “auto-conscientização” (GERHARDT, 1990, p. 1153).

Ainda segundo Gerhardt, em um primeiro momento, a sociologia das doenças crônicas adotou um ponto de vista ingênuo sobre a realidade, justificado por um papel político de intervenção sobre o real, por meio do qual procurou "dar voz aos excluídos". Em um segundo, a autocrítica sobre esse ponto de vista: a) abriu o debate sobre a validação do conhecimento científico; b) permitiu explorar novas relações entre pesquisadores e pesquisados; c) conduziu à admissão da existência de conflitos de interesses em diversos âmbitos da pesquisa; d) requisitou a reflexão sobre as relações existentes entre a ordem interpretativa dos pesquisados e a dos pesquisadores.

Essa passagem de uma ordem interpretativa à outra e o desafio por ela colocado ao pesquisador já havia sido apontada por Bourdieu (1999), ao alertar para o perigo de realizar uma sociologia ingênua. Posteriormente, esse autor retomou a questão, ao refletir sobre a relação entre a entrevista e a narrativa, apontando como o pesquisador pode ser capaz de se colocar no lugar do pesquisado, ou seja, "situar-se em pensamento no lugar que o pesquisado ocupa no espaço social" (Bourdieu, 1997, p. 699). De outro lado, convida o leitor a entender a situação de entrevista como "uma forma de exercício espiritual, visando a obter, pelo 
1344 esquecimento de si, uma verdadeira conversão do olhar que lançamos sobre os outros nas circunstâncias comuns da vida” (Bourdieu, 1997, p. 704).

Essas reflexōes deixam ver como a narrativa pode ocupar diferentes lugares na pesquisa. Com base nessa ideia, foram realizadas entrevistas semiestruturadas com trabalhadores braçais, com diagnósticos de doenças crônicas, tais como: hipertensão, diabetes, lombalgias, etc. Esses sujeitos foram convidados a situar a problemática de saúde no contexto de suas histórias de vida, com a finalidade de explicitar a experiência de adoecimento crônico de um determinado grupo.

Os entrevistados foram selecionados dentre os pacientes de uma Unidade Básica de Saúde (UBS), em um município do interior do Estado de São Paulo, situada no interior da Central de Abastecimento de produtos hortifrutigranjeiros. A localização da UBS nesse território faz com que ela se organize de maneira diferente daquelas voltadas para a Atenção Básica com Estratégia de Saúde da Família, pois atende prioritariamente à população de trabalhadores com vínculo com a Central. Assim, Os critérios de inclusão para as entrevistas foram: a) ser trabalhador(a) braçal urbano do setor hortifrutigranjeiro; b) ser acompanhado(a) naquela Unidade, em vista de um problema crônico de saúde.

Esclarecia-se que a entrevista não consistia em um atendimento clínico. As entrevistas foram realizadas em um ambiente privado, sendo conduzidas por duplas compostas pelo pesquisador principal e um estudante de pós-graduação (em treinamento em técnicas qualitativas de pesquisa), com o triplo objetivo de produzir material empírico de pesquisa, contribuir para a formação de pesquisadores e produzir informação a ser inserida no prontuário médico. Todavia, esta última etapa não se concretizou, sobretudo, devido à necessidade de aprofundamentos no debate sobre a inserção da informação gerada por cientistas sociais nos prontuários médicos.

Ao longo do trabalho de campo, uma questão bastante presente para os pesquisadores foi a de como trabalhar esse material, pois certamente há diferentes formas de narrar os conteúdos de uma entrevista. Optamos pela reorganização dos relatos elaborando narrativas biográficas com as informações obtidas, ou seja, elaborando narrativas das narrativas.

Este artigo apresenta uma dessas narrativas e discute suas possibilidades metodológicas no contexto da pesquisa qualitativa sobre o adoecimento crônico. Procuramos, assim, sustentar o enfoque biográfico na (re) elaboração narrativa 
do depoimento em questão, com o objetivo de entrever elementos da história de vida, da trajetória vivenciada no processo de adoecimento, assim como do itinerário terapêutico do paciente entrevistado.

\section{A narrativa de uma narrativa: "Herança nervosa"-a história do Sr. Sebastiāo}

O Sr. Sebastião, com seus 47 anos (a entrevista foi realizada em junho de 2003), nasceu em uma pequena cidade do interior paulista. Ainda novo, mudou-se com seus pais para a Região Centro-Oeste, onde viveu até a adolescência. São anos muito felizes de sua vida, trabalhando com a família na roça, sem grandes preocupações. O Sr. Sebastião fala com nostalgia desse tempo, quando não havia muito dinheiro, mas havia fartura.

Ele é o quarto de seis filhos, sendo o mais apegado ao pai. Após alguns anos, quando já alcançava a adolescência, este se mudou para Campos ${ }^{2}$ para trabalhar no setor hortifrutigranjeiro. Pouco tempo depois, ao completar 18 anos, seguiu os passos de seu pai. Ao chegar a Campos, o Sr. Sebastião foi morar com o pai, empregando-se em uma grande empresa da região. Demonstrando grande empenho no trabalho e um bom relacionamento com seus colegas, permaneceu nessa empresa por alguns anos. Desse modo, conseguiu construir uma edícula no fundo do terreno de seu pai, para ter maior independência.

O Sr. Sebastião casou-se. Construiu uma casa em outro terreno, onde passou a viver com sua esposa. Nesse momento, passou a trabalhar na mesma firma do pai, como carregador, onde já completou 23 anos de trabalho. Trabalhando sempre como autônomo, não contribuiu para a previdência, durante boa parte desse tempo, estando ainda um pouco longe de se aposentar. Nessa firma, ele presta serviço, há muito tempo, para dois produtores rurais, ocupando-se em boa parte da semana e dos finais de semana. Com ambos os produtores, mantém uma grande amizade e desfruta de grande confiança. Além de realizar carregamentos de frutas e de flores, ele exerce atividades de compra e venda para esses produtores.

A rotina do Sr. Sebastião é a seguinte: acorda todos os dias às $3 \mathrm{~h} 30 \mathrm{~min}$, anda uns cinco quilômetros e chega ao trabalho por volta das $4 \mathrm{~h}$. Em geral, às 12 h já terminou o serviço, pondo-se a caminho de casa. Essa rotina já existe há mais de duas décadas, sendo que as caminhadas são muito importantes para ele. O Sr. Sebastião gosta de ficar sozinho, não se acostuma com agitação, barulho 
1346 e lugares com muitas pessoas. Ao chegar em casa, sente-se "desinquieto", com um desassossego que não o abandona. Ainda assim, descansa um pouco à tarde, em vista do grande esforço físico feito desde a madrugada. Não demora, fica angustiado por estar em casa. Para ele, seria excelente se conseguisse trabalhar ininterruptamente, ou se ganhasse o suficiente para viajar bastante. Mesmo assim, mantém bom relacionamento com a esposa e seus dois filhos. Seu filho é um rapaz de 23 anos que está terminando a faculdade em um curso de análise de sistema e trabalha em uma grande multinacional, como programador. Sua filha é uma menina de 16 anos que gosta da área da saúde. Ela fez cursos de primeirossocorros, recém-ingressou em um curso técnico, de curta duração, pretendendo seguir seus estudos na área de enfermagem.

O Sr. Sebastião diz que "a esposa é uma grande companheira que, além de ajudar na complementação da renda da casa, vendendo bolos, sempre o apoiou durante toda a vida conjugal". Mesmo assim, persiste o desassossego. Basta entrar em casa para que comece a se sentir ansioso. Ele imagina coisas ruins acontecendo consigo ou com seus familiares. Dormir não consegue, tem pesadelos. Recentemente, contou mais de 20 dias sem dormir. O Sr. Sebastião é muito claro ao falar do problema que o aflige: depressão. Ele localiza com precisão a primeira vez em que sentiu os sintomas, há cerca de 30 anos.

Quando ainda trabalhava em seu primeiro emprego, logo que chegou a Campos, entrou em atrito com colegas de trabalho, surpreendendo a todos. Passou pelo médico da empresa, que o encaminhou para um atendimento psiquiátrico. Foi internado em um hospital psiquiátrico da cidade, onde permaneceu por dois meses. Naquele momento, a explicação para o seu problema de saúde foi encontrada, pela equipe médica, no seu cotidiano de trabalho. O Sr. Sebastião trabalhava no período noturno, arduamente, em um ambiente totalmente diferente daquele em que vivia anteriormente. Assim, vivia uma situação estressante, prolongada, gerando o que é por ele designado como "estafa". Como decorrência, não podia ouvir barulhos altos, especialmente criança chorando em casa e televisão alta. Sem conseguir lidar com essas situações corriqueiras em sua casa, nervoso, o Sr. Sebastião procurava sair, evitando discutir com a esposa. Agindo assim, ele afirma ter evitado, inclusive, agredir sua família. O Sr. Sebastião tem muito orgulho de seus filhos, mantendo com eles uma relação muito afetuosa. Quanto à esposa, ele só tem comentários positivos a fazer. Chega 
mesmo a dizer que se não fosse a existência de sua família, que lhe dá forte motivação e apoio para seguir em frente, já não estaria vivo há muito tempo. Durante todos esses anos, não viu o alívio de seus sintomas, mas somente o aumento do seu sofrimento. Não encontrou sossego, nem aconchego em seu lar. Apesar disso, só recentemente chegou a revelar para sua esposa uma parte mais obscura de seus pensamentos e de seu sofrimento, calados em si durante todo esse tempo. Há alguns poucos anos, voltando do trabalho para casa, como de costume, o Sr. Sebastião atravessava uma fazenda em que gostava de passar. Lá encontrou pessoas conhecidas, com as quais gastou algum tempo em conversas. Logo após, começou a vagar, sem rumo, evitando chegar a sua casa. Sua família fica preocupada e começa a procurá-lo. Já bastante aflito, seu filho, com o velho carro da família vasculha a região. Encontra, por fim, seu pai.

Chegando a casa, o Sr. Sebastião tem uma séria conversa com a esposa, revelando que há muito pensa em suicidar-se. Sem compartilhar esse desejo com mais ninguém, ele continua sua vida, passando por diversos médicos, em busca de solução. Triste e tomado por uma inquietude sem fim, com uma constrangedora propensão ao choro, sentindo fortes dores de cabeça, com pensamentos suicidas, ele passa por diversas consultas no centro de saúde de seu bairro e em hospitais. Para a insônia, pesadelos e ansiedade, toma meio comprimido de Diazepan, toda noite. Foi encaminhado pelos serviços de atenção primária para o ambulatório de neurologia de um hospital universitário, onde realizou eletroencefalograma. Não foi encontrada nenhuma alteração funcional. Recebeu novo encaminhamento, desta vez para atendimento psicológico (não havia sido realizado à época da entrevista). Além disso, experimentou um tratamento homeopático, sem, no entanto, tolerar os medicamentos. O Sr. Sebastião refere sofrer de gastrite "nervosa", diagnosticada através de endoscopia. Por esse motivo, não tolera a diluição em álcool, feita nos remédios homeopáticos, nem a Dipirona indicada para a sua dor de cabeça. Também descobriu recentemente, através de um ultrassom, ter um pequeno problema no fígado. Ele lamenta não poder comer alimentos “ácidos", especialmente, suco de laranja, frutas, tomate e carne de panela. Também evita o café. Insiste no leite, mesmo diante da queimação no estômago e do desarranjo intestinal. Sente-se "fraco" sem esse alimento. Sua mãe, que mora bem próxima, é categórica: "Basta dar menos atenção ao que come!” Ele obedece. No entanto, não encontra efeito. Segue, também, as orientações médicas. Só não transige em relação ao seu trabalho. 
1348 Não admite qualquer afastamento. Não só pelo dinheiro, mas pelo que o trabalho representa em sua vida. Iniciou nesse serviço por intermédio de seu pai.

Este morreu poucos anos depois de vir para Campos, vítima de câncer no estômago. O Sr. Sebastião conta que, após o trabalho, ia ficar com seu pai, no hospital, durante o longo período de internação por que passou. Ele associa o surgimento de sua "depressão" à perda do pai. Um mal que acompanha sua família há muito tempo. Seu pai viu dois irmãos e uma irmã suicidarem-se. $\mathrm{O}$ Sr. Sebastião conta que um dos tios matou-se com veneno, após descobrir estar com uma doença grave. Outro se matou com um tiro na cabeça, sem motivos específicos. Finalmente, a tia, diagnosticada com problemas mentais, matou-se tomando soda cáustica (o Sr. Sebastião refere ter assistido a sua morte, quando tinha ainda seis anos). O Sr. Sebastião afirma sempre ter sentido uma forte ligação afetiva, de gênio e de caráter, com seu pai. Os males que agora sente afligiram também seu pai - a depressão, o nervoso, a insônia.

Além disso, o irmão mais novo do Sr. Sebastião, assim como ele, passou dois meses internado com depressão. O Sr. Sebastião não encontra confiança em si mesmo. Apoia-se em Deus, na família e na ciência (profissionais de saúde) para tentar manter um equilíbrio emocional. Para ele, os profissionais de saúde, além de "clínicos", são "conselheiros" que o ajudam muito no enfrentamento de seu sofrimento. Ele procura bastante a equipe de enfermagem do ambulatório da empresa, com quem mantém uma grande relação de confiança. Sua família o apóia em casa, mantendo com ele uma relação de afeto e respeito. Além disso, tanto sua esposa, sua sogra, seu cunhado, quanto seu patrão e seus amigos, o estimulam bastante a sair para passear, para espairecer, para quebrar sua rotina. O Sr. Sebastião vai, de vez em quando, para as chácaras de familiares e amigos, em geral, passar alguns dias sozinho ou, no máximo, com o filho. Nesses momentos, ele se sente bem, com liberdade, de pé no chão, sem camisa. Gosta de passear pelos arredores, sem preocupação ou pensamento ruim. Ele é categórico ao afirmar que não aguenta mais viver na cidade, com toda a sua violência, as aglomerações, o custo de vida. Apesar de conseguir pagar as contas da casa com seus dois salários mínimos mensais, ele não se esquece de que precisa ganhar hoje o dinheiro da comida de amanhã. Por vezes, ele se imagina prazerosamente sentado em uma cadeira, olhando a natureza, na varanda de um sítio. Porém, sente-se atrelado à sua vida de trabalho e subjugado pelo que denomina seu 
"sistema nervoso". Ao andar na rua, sente que os outros o veem de maneira diferente, como se tivesse algo estranho. Para todos os efeitos, para a família, colegas e amigos, ele é "estressado", ainda que pacato e bom companheiro. Para si mesmo, ele guarda a identidade de "depressivo". Uma vez que não pode confiar inteiramente nos homens (nem em si mesmo), considera que, no plano superior, há quem consiga iluminar seu caminho. Enquanto aguarda o apoio psicológico de que tanto necessita, frequenta, três vezes por semana, o culto em uma igreja evangélica, levando a vida, marcada por sua "herança nervosa”.

\section{A narrativa e seus significados}

A entrevista que originou essa narrativa foi realizada em um local que predispunha ao acercamento da doença do ponto de vista de sua patologia orgânica, pois se tratava de um Centro de Saúde. Com duração de uma hora e meia, a entrevista foi gravada e transcrita, gerando 25 laudas.

Após várias leituras do material, um dos autores construiu uma narrativa a partir da entrevista, apresentando-a aos demais, que incorporaram ou retiraram trechos. Destaca-se que esse exercício foi o de transformar informação (dados brutos da entrevista) em conhecimento (dados tratados da narrativa), para que fosse incorporado ao prontuário do paciente, como uma evidência qualitativa de sua experiência com a doença. Essa pode ser uma contribuição fundamental das ciências sociais para o campo da saúde; no entanto, a incorporação das narrativas aos prontuários não chegou a ser realizada, sendo este um dos limites da experiência aqui relatada.

Estamos seguros de que a narrativa biográfica, produzida por pesquisas qualitativas, pode representar um recurso importante para reflexão e atuação sobre o cuidado prestado aos pacientes. Acreditamos tratar-se de um enfoque de fácil assimilação na lógica de organização do atendimento clínico, na medida em que se dirige para a singularidade do caso. Ainda mais, permite traçar relações com contextos e problemáticas mais amplas - tanto aquelas presentes no próprio texto quanto aquelas possibilitadas a partir da sua discussão.

De maneira geral, no processo de entrevista a primeira mensagem transmitida aos entrevistados era a de que não iríamos realizar uma "consulta" médica, mas que desejávamos conhecer um pouco de suas vidas, de seus trabalhos e de suas condiçôes de saúde, incluindo as de seus familiares. Solicitávamos que relatassem 
1350 o itinerário de seus cuidados de saúde com profissionais, assim como a outras formas alternativas de tratamento. Apesar de solícitos, nem sempre construíam relatos fluentes, necessitando da intervenção do entrevistador, formulando questôes e reconduzindo para alguns aspectos mais específicos.

$\mathrm{O}$ desconcerto demonstrado por alguns entrevistados em tecer um relato que extrapolava, em muito, o foco de interesse usualmente assumido pelos profissionais de saúde pode ter-se intensificado, em alguns casos, pelo fato das entrevistas terem sido realizadas em um consultório médico, com o prontuário do paciente disposto sobre a mesa. Essa ideia fica reforçada ao observarmos que, frequentemente, quando os entrevistadores concluíam a entrevista, perguntando aos entrevistados se gostariam de fazer algum comentário sobre a entrevista ou sobre algum assunto abordado, estes perguntavam sobre a etiologia ou prognóstico de seus problemas de saúde, como se estivessem se dirigindo a seus médicos.

Sabe-se que "as narrativas problematizam a relação entre cultura ou formas simbólicas e experiência. [...] Assim, a narrativa é uma forma na qual a experiência é representada e recontada, e os eventos são apresentados como tendo uma ordem significativa e coerente". (GOMES; MENDONÇA, 2002, p. 118) Além disso, é sabido que, de maneira geral, o que se observa em uma narrativa pessoal é o processo, destacado por Da Matta (1997), da passagem de indivíduo a pessoa, ou seja, daquele que é sujeito indiferenciado, para quem as regras e a repressão foram feitas, para o que merece solidariedade e um tratamento diferencial. Na narrativa construída a partir do discurso do Sr. Sebastião não é diferente, pois foi mantida a perspectiva de o entrevistado se tornar sujeito de sua história, que, ao contá-la, vai ressaltar aqueles pontos que mais tocam a sua experiência de vida - nesse caso específico, particularizando aspectos do seu sofrimento.

Outro ponto que a narrativa explora é o limite do "paradigma biomédico, [que] não inclui uma compreensão integral sobre o que as pessoas sentem e vivem em torno do adoecer". (GOMES; MENDONÇA, 2002, p. 119). Na construção da narrativa do caso do Sr. Sebastiáo, procuramos produzir um tipo de conhecimento centrado na sua experiência de adoecimento. Partimos do pressuposto de que é "a partir da experiência que os pacientes constroem as narrativas de doenças com as quais se comunicam com os profissionais da saúde" (GOMES; MENDONÇA, 2002, p. 119), em busca dos significados atribuídos ao sofrimento, explorando o relato e reelaborando-o em uma 
narrativa que procura enquadrar biograficamente o processo de adoecimento, para além da perspectiva biomédica.

Assim, se o Diazepan está incorporado na rotina do Sr. Sebastião, seu sofrimento não é aí contido, extrapolando o corpo biomedicamente definido. É na própria elaboração da narrativa de sua história de vida que se revelam os sentidos do seu adoecer e das implicaçôes destes para a maneira como caminha a vida, marcado pelos passos de seu pai, de quem herdou a honra do trabalho e o sofrimento do "nervoso". Nesse imbricamento entre a honra e o "nervoso", entre sua trajetória individual e familiar, entre seu passado e presente, o Sr. Sebastiāo encontra uma identidade entre o self e o sofrimento relatado.

A passagem do Sr. Sebastião pelos serviços de saúde não alivia, ainda que legitime, a realidade do sofrimento com sintomas clinicamente reconhecidos, prescriçôes medicamentosas e encaminhamentos. Nesse prolongado processo, vive uma incessante inquietude que o impulsiona a buscar, no caminhar entre a casa e o trabalho, sua terceira margem do rio, eternizada e atualizada em seu desígnio familiar. Sr. Sebastião continua sua lida com o sofrer, mas sustenta a honra de ser um bom provedor, com uma vida de trabalho na cidade, marcada pelo sentido de ser homem e pai de família. Ao mesmo tempo, ele suporta a sua sina de "nervoso". Segue calado, quase sem comunicar esse sofrimento, a não ser através dos medicamentos e consultas - ou em situaçôes-limite, como aquela em que foi resgatado pelo filho. São poucos (ou mesmo inexistentes) os espaços, encontrados por Sr. Sebastião, para a realização de trocas solidárias dos sentidos do sofrer.

\section{Alcances e limites da análise}

Cabras, Camargo Jr e Llerena (2002), ao refletirem sobre as diferentes maneiras como a narrativa foi tomada enquanto um objeto de estudo das ciências sociais, no campo da saúde, se referem a uma interessante tipologia entre narrador, narrativa e doença. Segundo os autores, essas relações se organizariam em três tipos principais: "doença como narrativa" - narrador, doença e narrativa combinamse numa só pessoa, no caso, portanto, as narrativas que os pacientes fazem a seu médico; "narrativas sobre doença" - uma narrativa que traz em si conhecimentos e ideias sobre as doenças, nesse sentido, as que os médicos fazem de seus pacientes, entretanto, nada impedindo que os doentes também as façam, misturando-as, em determinados pontos, com aquelas do primeiro tipo; e, por fim, "narrativa como 
1352 doença" - significando situações nas quais uma doença gera distúrbios na narração" (CABRAS; CAMARGO JR.; LLERENA, 2002, p. 565).

A esses tipos acrescentamos um quarto, que denominamos de narrativa construída pelo pesquisador, a qual parte de extenso volume de informações coletadas em entrevistas para construir evidências qualitativas sobre o narrador, a doença e sua narrativa original. Esta forma visa a alcançar, entre outros: 1) a construção do mundo da doença como alteração corporal e desintegração do mundo social; 2) a reconstrução da história de vida; 3) a explicação e o entendimento da doença e de suas relaçôes nos contextos individuais, sociais e culturais; 4) a transformação do individual para o pessoal e deste para o coletivo (GOMES; MENDONÇA, 2002).

A narrativa "Herança nervosa" procura explorar alguns desses pontos. Para tanto, buscamos enquadrar o sofrimento do Sr. Sebastião em um contexto biográfico, entrelaçando a narrativa original do paciente com a narrativa dos pesquisadores. Estivemos interessados na singularidade do caso, nas particularidades encontradas no campo de pesquisa e no quadro geral da problemática enfrentada. No entanto, entendemos que a narrativa construída pelos pesquisadores apresenta uma possibilidade metodológica que toma a narrativa como centro da pesquisa qualitativa, pois não contrapõe pesquisador e pesquisado em uma relação de subalternização e/ou reificação.

Adotamos o entrelaçamento entre a interpretação de primeira ordem (dos entrevistados) com a interpretação de segunda ordem (dos pesquisadores), para avançar em relação aos textos tradicionalmente produzidos, que procuram apresentar essa segunda ordem interpretativa em um texto corrido, entremeado (ou mesmo entrecortado!) por falas dos entrevistados. Neste último caso, os trechos das transcrições citados têm a função de autorizar as análises já efetuadas sobre o conjunto do material empírico, assumindo, por vezes, um caráter meramente ilustrativo de algo já afirmado nas palavras do pesquisador. Sendo assim, podese afirmar que a análise já se deu na sucessão de recortes realizados no material empírico, na organização desse material a partir de categorias empíricas (em geral, temáticas), na busca de relaçóes entre o contexto específico do universo investigado e os contextos mais gerais dados pelas categorias analíticas (MINAYO, 1996).

Em que pese o fato de que a ciência se constrói em oposição ao senso comum, os recortes e reelaboraçóes produzidos nesse tipo tradicional de texto analítico produzem uma grande fragmentação dos pontos de vista investigados. Nesse 
sentido, em alguns casos, cede-se à "ilusão da transparência” dos dados, na medida em que não é exercitada a reflexividade sobre as condições de produção do "dado", tomando as análises como uma consequência direta do material empírico apresentado. Somente mais recentemente, pesquisadores procuraram experimentar deslocamentos dessa estruturação, propondo uma postura inclusiva no contexto geral da pesquisa qualitativa.

Uma possibilidade aberta, em nossa investigação, foi a de inserir as narrativas dos casos individuais no prontuário médico, com o objetivo de discuti-las com os pacientes e com os profissionais de saúde que os atendem. Uma vez que a elaboração narrativa implica um movimento reflexivo em que o relato elaborado inscreve sentidos aos eventos descritos, inserindo-os em uma temporalidade situacionalmente definida, acredita-se que a apresentação e a discussão do material empírico ocasionem um novo momento reflexivo, aberto a novas possibilidades narrativas (HOONAARD, 2008).

A discussão dos alcances e limites deste trabalho com os alunos de pósgraduação, envolvidos nessa experiência de pesquisa, já representa um desdobramento importante, na medida em que os alunos puderam vivenciar as condiçôes de produção presentes na técnica de entrevista; assumir o desafio de produzir narrativas com o foco biográfico de uma pessoa com alguma condição crônica de doença, assim como participar do debate sobre a importância do trabalho narrativo para o ensino, a pesquisa e cuidado em saúde.

\section{Considerações finais}

Consideramos que um ponto central desta análise se assenta na compreensão de que a narrativa constitui um "refinamento da metodologia interpretativa nas ciências humanas” (BROCKMEIER; HARRÉ, 2003). A utilização do método da narrativa ocupou, inicialmente, um espaço periférico no campo do conhecimento sociológico das doenças, mas, atualmente, ocupa um lugar predominante, por permitir interpretar aspectos nucleares da elaboração da experiência de adoecimento em seus contextos sociais específicos.

A narrativa deixa de ser um mero instrumento comunicacional, o qual dá acesso a uma realidade anterior, para ser tomada como o próprio local de acontecimento da análise, ou seja, da elaboração de interpretações que partem de relaçôes definidoras dos sentidos do sofrimento, adoecimento e cura. 
Isso implica, no campo da saúde, a passagem da informação indiferenciada para o conhecimento personalizado, a qual explicita os distanciamentos, aproximações, conjugações e interpelações entre a experiência/posição do doente e do cuidador. Essa explicitação convida à reflexão sobre os parâmetros técnicos, éticos, teóricos, epistemológicos e (micro)políticos do cuidado em um contexto situacional.

Esse interesse pelo outro nos estudos socioantropológicos da área de saúde deve perpassar não somente a lógica da investigação, mas avançar sobre a lógica da apresentação, desencadeando rupturas epistemológicas que gerem fissuras nas estruturas narrativas instituídas na pesquisa qualitativa. Em uma palavra, esse interesse deve ser estruturante de caminhos ainda não tão demarcados, mantendo-se seu caráter a um só tempo incômodo e mobilizador.

\section{Referências}

BOURdiEU, P. (Org.). A miséria do mundo. Petrópolis: Vozes, 1997.

BOURDIEU, P.; CHAMBOREDON, J-C.; PASSERON, J-C. A profissão do sociólogo: preliminares epistemológicos. Petrópolis: Vozes, 1999.

BROCKMEIER, J.; HARRÉ, R. Narrativa: problemas e promessas de um paradigma alternativo. Psicologia: reflexão e crítica, v. 16, n. 3, p. 525-535, 2003.

BRUNER, J. Life as narrative. Social Research, v. 54, n. 1, p. 11-32, 1987.

CABRAS, M.H. de A.; CAMARGO JR, K. R.; LLERENA JR., J.C. A epistemologia narrativa e o exercício clínico do diagnóstico. Ciência e Saúde Coletiva, v. 7, n. 3, p. 555-569, 2002. CHARON, R. Narrative and medicine. The New England Journal of Medicine, v. 350, n. 9, p. 862-864, fev 2004 .

CHARON, R. The self-telling body. Narrative Inquiry, vol. 16, n. 1, p. 191-200, 2006.

CUNHA, M.I. Conta-me agora! As narrativas como alternativas pedagógicas na pesquisa e no ensino. Revista da Faculdade de Educação, v. 23, n. 1-2, 1997.

CZARNIAWSKA, B. Narratives in social science research. London: Sage, 2006.

DAMATTA, R. Carnavais, malandros e heróis. Para uma sociologia do dilema brasileiro. Rio de Janeiro: Rocco, 1997.

FONTE, C.A. A narrativa no contexto da ciência psicológica sob o aspecto do processo de construção de significados. Psicologia - Teoria e Prática, v. 8, n. 2, p. 123-131, dez. 2006.

GERHARDT, U. Introductory essay -qualitative research on chronic illness: the issue and the story. Social Science and Medicine, v. 30, n. 11, p. 1.149-59, 1990. 
GOMES, R.; MENDONÇA, E.A. A representação e a experiência da doença: princípios para a pesquisa qualitativa em saúde. In: MINAYO, M.C.S.; DESLANDES, S.F. (Org.). Caminhos do pensamento: epistemologia e método. Rio de Janeiro: Fiocruz, 2002. p.1 09-32. GREENHALGH, T.; HURWITZ, B. Narrative based medicine: Why study narrative? British Medical Journal, v. 2, n. 318, p. 48-50, 1999.

HOONAARD, W. van den. A explosão da bolha: relações entre pesquisador e participantes pesquisados. In: GUERREIRO, I.C.Z..; SCHMIDT, M.L.S.; ZICKER, F. (Org.) Ética nas pesquisas em ciências humanas e sociais na saúde. São Paulo: Hucitec, 2008.

HYDÉN L. Illness and narrative. Sociology of Health and Illness, v. 19, n. 1, p. 49-64, 1997.

KLEINMAN, A. The illness narratives. Suffering, healing \& the human condition. Nova York: Basic Book, 1988.

LIRA, G.V.; CATRIB, A.M. F.; NATIONS, M. K. A narrativa na pesquisa social em saúde: perspectiva e método. Revista Brasileira em Promoção à Saúde, v. 16, n. 1/2, p. 59-66, 2003. MATTINGLY, C.; GARRO, L.C. Narrative representations of illness and healing, Social Science and Medicine, v. 38, n. 6, p. 771-774, 1994.

ROBINSON, I. Personal narratives, social careers and medical courses: analysing life trajectories in autobiographies of people with multiple sclerosis. Social Science and Medicine, v. 30, n. 11, p. 1173-1186, 1990.

SILVA, D.G.V.; TRENTINI, M. Narrativas como técnica de pesquisa em enfermagem. Revista Latino-americana de Enfermagem, v. 10, n. 3, p. 423-432, maio-junho 2002.

\section{Notas}

${ }^{1}$ Dentre as publicações especializadas destaca-se: JNT: Journal of Narrative Theory, fundado em 1971; The Journal of Narrative Technique, publicado pelo Department of English Language at Eastern Michigan University; Narrative, revista oficial da International Society for the Study of Narrative; Narrative Inquiry, continuação do Journal of Narrative and Life Historry (1990-1997).

${ }^{2}$ Os nomes do entrevistado e da cidade são fictícios. 


\section{Abstract}

\section{The illness' experience: from interview to narrative}

This paper emphasizes the importance of narrative as a way of describing life experiences, in the special case of the illness' experience. Its starting point is the narrative as a research tool. The material collected in this interview was twofold: served for training graduate students in interviews and placed the issue of health of a group of workers with diagnoses of chronic diseases like hypertension, diabetes, back pain, etc. We searched for reports made in a single interview, putting the illness in the context of life history, in order to grasp the "experience" of the subject and to solve the problem of disease as users of a health center in a city in São Paulo State. Concerning the organization of the material, we chose the reorganization of oral history by developing a narrative with such information. So this is a narrative of an original narrative that, from a semi-structured interview, was organized as case study, with biographic approach, aiming to observe life history elements, personal illness trajectory, and therapeutic itinerary. We concluded that the narrative represents important resources to produce knowledge, in teaching, research and care perspectives.

Key words: narrative, illness' experience, interview, research methodology. 